OPEN ACCESS

Edited by:

Ryan Pollyea,

Virginia Tech, United States

Reviewed by:

Binoy K. Saikia,

North East Institute of Science and

Technology (CSIR), India

Debanjan Chandra,

Indian Institute of Technology

Bombay, India

*Correspondence:

Udayan Singh

udayan.singh@northwestern.edu

Specialty section

This article was submitted to Negative Emission Technologies,

a section of the journal

Frontiers in Climate

Received: 11 May 2021

Accepted: 28 June 2021

Published: 22 July 2021

Citation:

Singh U, Sharma N and Dunn JB

(2021) Revisiting Geologic Storage

Potential in Unconventional

Formations is Key to Proactive

Decision Making on CCS in India.

Front. Clim. 3:708320

doi: $10.3389 /$ fclim.2021.708320

\section{Revisiting Geologic Storage Potential in Unconventional Formations Is Key to Proactive Decision Making on CCS in India}

\author{
Udayan Singh $^{1 *}$, Naushita Sharma ${ }^{2}$ and Jennifer B. Dunn ${ }^{1}$ \\ ${ }^{1}$ Department of Chemical and Biological Engineering, Northwestern University, Evanston, IL, United States, ${ }^{2}$ School of \\ Sustainable Engineering and the Built Environment, Arizona State University, Tempe, AZ, United States
}

Global energy modeling exercises project significant deployment of $\mathrm{CO}_{2}$ capture and storage (CCS) to bridge the gap between India's pledged climate commitments and the $1.5^{\circ} \mathrm{C}$ target. Despite advances in laboratory analyses and process modeling, the information on geologic storage potential in India is limited. Prior studies indicate that the vast majority of storage potential exists in saline aquifers (50-300 Gt- $\left.\mathrm{CO}_{2}\right)$; though, this might be overestimated. These estimates also estimate the theoretical potential in coal seams to be $<5 \mathrm{Gt}-\mathrm{CO}_{2}$ while shale basins have not been evaluated as geologic $\mathrm{CO}_{2}$ sinks on a systems level. Based on several recent climate developments and CCS best practices, we suggest revisiting these potential estimates. We demonstrate how revisiting some assumptions might enhance the coal repository available as a sink by a factor of 7-8. We also present proof-of-concept analysis to show that Indian shale reservoirs might have suitable $\mathrm{CO}_{2}$ adsorption capacity. With detailed recommendations for revising these estimates, we present a methodological framework for incorporating the best practices for coal seam and shale basin storage potential. Based on source-sink mapping exercises, we also argue that unconventional basins in India are especially relevant because of their proximity to large point sources of $\mathrm{CO}_{2}$.

Keywords: geologic sequestration of $\mathrm{CO}_{2}$, unconventional formations, India, storage potential, coalbed methane, shale reservoir

\section{INTRODUCTION}

$\mathrm{CO}_{2}$ capture and storage (CCS) is projected to be an important part of India's future energy mix. While the current commitments of the Government of India within the Paris Agreement framework do not explicitly mention this technology, more ambitious targets would near-certainly require large-scale CCS. A consensus of integrated assessment modeling (IAM) studies indicate that 7-10 Gt- $\mathrm{CO}_{2}$ would be need to be cumulatively sequestered by 2050 for meeting the $2^{\circ} \mathrm{C}$ national carbon budget (Shukla et al., 2015; Vishwanathan and Garg, 2020). These exercises project that $\mathrm{CO}_{2}$ could be captured from a wide-variety of sectors-coal and gas power, steel, cement, refineries, and lately, bioenergy and ambient air-but they do not have similar representation in detail for the storage of $\mathrm{CO}_{2}$. 
Based on the perceived importance of CCS outlined above, a number of country-specific studies have appeared looking at policy approaches (Gupta and Paul, 2019; Hiremath et al., 2021; IEA CCC, 2021), costs and energy penalty for $\mathrm{CO}_{2}$ capture (Yadav et al., 2016; Singh et al., 2017) and source-sink mapping (Garg et al., 2017). However, the literature on the downstream end of the CCS life cycle i.e., geologic sequestration is limited. While the laboratory-scale studies on the geomechanics of $\mathrm{CO}_{2}$ injection have continued to evolve, storage potential assessment has not been carried out post-2009 in India. These decadeold assessments (Singh et al., 2006; Holloway et al., 2009) were subject to large uncertainties, as acknowledged by the authors (Wuppertal, 2012), and indicated an overwhelming majority of geologic sink availability in saline aquifers.

\section{Objectives and Organization of This Perspective}

We see opportunities for research, ideally that is collaborative between industry and academic researchers, that could correct the ambiguities in storage potential and evaluate the realistic potential of CCS for emissions reductions commitments for India. This research would start with the re-evaluation of core assumptions in existing evaluations of CCS potential in coal beds/seams that would improve these estimates based on the latest projections on energy scenarios. It would then advance to new evaluations of the CCS potential in shale gas reservoirs. We also describe opportunities for matchmaking between emissions sources and CCS sites that can inform policy making.

We point out in "Prior studies and the need to look at unconventional formations" that the strategy of emphasizing saline aquifers could be reworked by prioritizing unconventional formations (coal and shale reservoirs) for geologic sequestration based on updated data availability and economic lucrativeness on part of the coal and hydrocarbon industries. We discuss coal and shale formations as potential $\mathrm{CO}_{2}$ sinks individually in "Storage potential considerations in coal seams" and "Storage potential considerations in shale formations" along with an approach to revise the first-order theoretical storage potential estimates for these reservoirs. These reservoirs are discussed separately because of their differing geologic conditions and level of understanding in India. For example, coal basins have been explored as potential $\mathrm{CO}_{2}$ sinks in existing literature (Singh et al., 2006; Holloway et al., 2009). In "Storage potential considerations in coal seams," however, we indicate the need for reworking of particular assumptions compared to what previous studies assume. To our knowledge, no similar study has been performed for Indian shale basins. That said, our understanding indicates that primary data from past studies could be reformulated for improved estimation for $\mathrm{CO}_{2}$ storage in both coal and shale formations. Once these considerations have been discussed, we provide recommendations for narrowing the $\mathrm{CO}_{2}$ storage estimates for coal and shale basins based on geographical and engineering criteria in "Moving beyond theoretical potential." Overall, we investigate the hypothesis that existing studies could be dramatically underestimating the potential for CCS in India by excluding coal and shale reservoirs.
It may be noted here that some studies indicate basalt formations as an unconventional reservoir, which is outside the scope of this paper. Here, we focus solely on coal and shale reservoirs. That said, basalt formations are an important thrust area in $\mathrm{CO}_{2}$ storage and significant work has been carried out in India and internationally (del Real and Vishal, 2016).

\section{PRIOR STUDIES AND THE NEED TO LOOK AT UNCONVENTIONAL FORMATIONS}

The initial estimates of geologic storage potential in India were presented by Dooley et al. (2005) and Singh et al. (2006). Both these studies revealed that the vast majority (>95\%) of sink availability was in saline aquifers. The cumulative potential within coal, oil and gas reservoirs was $<10 \mathrm{Gt}-\mathrm{CO}_{2}$, which is equivalent to about 4 years of India's $\mathrm{CO}_{2}$ emissions from point sources. This has led several policy-makers to see CCS apprehensively because aquifer storage is financially less appealing and poses risks to groundwater resources. For instance, IAM analyses-which are influential in policy-making-consider the previously published results as indicative of low CCS feasibility in such formations in India (Garg et al., 2017; Selosse and Ricci, 2017). A closer look, however, reveals that these projections of low CCS potential in India could be partially apportioned to contradictory assumptions about pore space availability.

On one hand, the assumptions about saline aquifers were very liberal due to lack of data availability. The storage potential for saline aquifers in the prior Indian studies were similar to the US DOE Carbon Storage Atlas methodology, where volumetric equation was a product of area, thickness, porosity, density and efficiency factor (DOE, 2015). In particular, the depth, porosity and thickness of reservoirs, which determine aquifers' potential as a $\mathrm{CO}_{2}$ sink, where characterized with global default values, not values that were specific to individual aquifers. For instance, the porosity was selected as $0.5 \%$ based on global defaults. This is because Indian groundwater surveys have been restricted to shallow depths $(<800 \mathrm{~m})$ with an emphasis on potable and agricultural water resources. As such, no large-scale brine collection has been carried out to gauge reservoir parameters, as has been done, say, by the USGS Brine Database in the United States (Blondes et al., 2016). This has led to some obvious ambiguities. For instance, default theoretical estimates show that the Ganga Basin has a large theoretical storage potential ( $\sim 80 \mathrm{Gt}-$ $\mathrm{CO}_{2}$ ) based on its geographical area. However, experts suggest that it might be 1-2 orders of magnitude less than estimated due to low salinity and unpredictable caprock availability. In fact, the authors of these studies have themselves pointed out that associated errors may be very significant and that these estimates were a function of the best data available at that time (Wuppertal, 2012).

Contrastingly, the storage potential in coal formations was estimated conservatively. While geological data was plentiful, these data were coupled with extremely restrictive economic and regulatory assumptions. For instance, it was assumed that coking coal, which is used for steel manufacturing would be mined out 
and therefore the mines from which it is sourced would not qualify for $\mathrm{CO}_{2}$ storage regardless of depth. The assumptions around coking coal particularly deserve attention due to falling steel production in India. In 2020, India's steel production reduced disproportionately by $10.6 \%$ even as the global reduction was $<1 \%$. Thus, there are strong indications that prior works have overestimated the extractability as well as demand of coking coal. Similarly, other reserves were considered mineable up to $600-800 \mathrm{~m}$ based on lucrative coal pricing structure of the time. It should be noted that further studies placed increasingly restrictive parameters of $90 \%$ storage efficiency (Singh and Mohanty, 2015) and removing lignite fields (Holloway et al., 2009) from consideration which reduced the sink availability from 5 to $4.5 \mathrm{Gt}-\mathrm{CO}_{2}$ and $0.4 \mathrm{Gt}-\mathrm{CO}_{2}$, respectively.

Recent evidence as well as new scientific literature indicates that these assumptions might require reframing. For instance, coal demand is increasingly scarce in $2 / 1.5^{\circ} \mathrm{C}$ scenarios, thus countermanding prior assumptions on most coking and noncoking coal being mined out and therefore, being unavailable for $\mathrm{CO}_{2}$ sequestration (Vishwanathan and Garg, 2020). These studies parallelly suggest increased demand for natural gas as a substitute for coal, which could be supplemented to some degree by enhanced methane recovery via $\mathrm{CO}_{2}$ injection in unconventional reservoirs. According to some media reports (Chaudhary et al., 2021) and expert "op-eds" (Garg, 2021; Parikh and Parikh, 2021), the Indian Government is mulling an aggressive net-zero target by 2050 which could further reduce future coal use. Recent statements by Coal India Limited, the state-owned coal company responsible for $>80 \%$ of India's coal production indicate that they foresee solar overtaking coal as India's primary power producer. Coal pricing is already less lucrative with a $\$ 6-7 / t-\mathrm{CO}_{2}$ coal "cess" or surcharge (Spencer et al., 2018; Malik et al., 2020). If less coal from higher depths is extracted, greater reservoir will be available for $\mathrm{CO}_{2}$ storage. In other words, earlier assumptions about these reservoirs being unavailable may have led to significant underestimation of storage potential in coal formations. Even if coal use were to continue, recent years have shown coal companies are apprehensive about underground mining due to safety concerns. Instead, they opt for near-surface deposits (Singh and Kumar, 2016).

Due to these emerging circumstances, we suggest a reframing of assumptions as well as policy narratives regarding unconventional formations as $\mathrm{CO}_{2}$ sinks (in subsequent sections). Moreover, to avoid internally inconsistent assumptions, we suggest that future studies should use the storage potential pyramid (Supplementary Figure 1 of the SI) as a way of making apples-to-apples comparisons. These practices suggest that in the first step, the theoretical potential may be calculated, which is indicative of pore space availability. This could be constrained based on geologic, engineering, economic and ultimately, source-sink mapping considerations which reduces the actual capacity to $10-20 \%$ of the theoretical capacity (Yu et al., 2019). As we demonstrated, prior estimates for saline aquifers correspond to theoretical potential (bottom of the pyramid) while those for coal reservoirs have a mix of inbuilt geologic and economic assumptions, which might have prevented a robust theoretical estimate for unconventional formations. An increased focus on unconventional formations could also increase business opportunities for CCS in India. Across the world, enhanced hydrocarbon recovery has been the preferred sink for existing and upcoming CCS projects (Global CCS Institute, 2020). A sustained focus on unconventional basins could similarly provide business lucrativeness to both public and private extractive industries to pursue CCS.

\section{STORAGE POTENTIAL CONSIDERATIONS IN COAL SEAMS}

Coal seams are an often-discussed storage formation for $\mathrm{CO}_{2}$ especially since publication of the IPCC Special Report on CCS (Benson et al., 2005). They have the potential to offer injectability at much shallower depths (as low as $300 \mathrm{~m}$ ) because of coal's highly adsorptive structure which differs from other formations considered suitable for $\mathrm{CO}_{2}$ storage (ARI, 1998; Das and Dutta, 2017). Primarily, injection in coal seams is considered for enhanced coalbed methane recovery $(\mathrm{ECBM})$ where $\mathrm{CO}_{2}$ sequestration leads to improved productivity in coalbed methane (CBM) fields where production might be tapering. While ECBM has not demonstrated similar maturity as enhanced oil recovery (EOR), it offers comparable theoretical potential. For instance, the US Carbon Storage Atlas (DOE, 2015) estimates that the sequestration potential in coal seams in the US is $54-113 \mathrm{Gt}-$ $\mathrm{CO}_{2}$, which is about half of that available in oil and gas reservoirs (188-232 Gt- $\mathrm{CO}_{2}$ ). Results from pilot studies in the US, China and Australia have also shown increased CBM production accompanying reliable retention of $\mathrm{CO}_{2}$ with no discernible groundwater hazards (Zhou et al., 2013; Pashin et al., 2015).

In India, ECBM potential has been gauged at $0.3-5 \mathrm{Gt}$ $\mathrm{CO}_{2}$ despite the overall coal resource being similar to that of the US. As stated in "Prior studies and the need to look at unconventional formations," this was a function of highly constraining assumptions around depth criteria based on economic considerations of 1.5 decades ago. We have already demonstrated that these assumptions might need to reframed based on aggressive climate constraints and technological issues surrounding extraction of deep-seated coal deposits. Here, we look at the coal resources from a quantitative viewpoint (Supplementary Table 1 of the SI).

First, prior analyses assume that all coking coal and superior grade non-coking coal would be treated as extractable up to depths of $1,200 \mathrm{~m}$ (thus not treated as a storage site). Even for inferior grade non-coking coal, they assumed that extraction would occur up to depths of $600 \mathrm{~m}$. This leads to a coal repository suitable for sequestration at about $15 \mathrm{Gt}$. However, once we consider the non-coking coal in the depth $300-600 \mathrm{~m}$, this substantially increases the coal repository available to $106 \mathrm{Gt}$. This means that even if only the depth criteria around noncoking coal is relaxed, the coal repository increases by a factor of 7. Once coking coal in the depth $300-1,200 \mathrm{~m}$ is included in this repository, it further increases to $120 \mathrm{Gt}$ (i.e., an overall increase by a factor of 8 ). It is true that storage at shallower depths may not offer similar adsorption capacity as depths of more than $600 \mathrm{~m}$ (Mahanta and Vishal, 2020). That said, it is widely recognized 
that the mechanism of $\mathrm{CO}_{2}$ storage in coal seams is different from that in aquifers or oil and gas reservoirs (i.e., free reservoirs). Coal has an extraordinarily high rate of adsorption due to its dual-cleat structure which means that storage might be possible at much shallower depths than the standard of $800 \mathrm{~m}$ considered for other deposits. Indeed, based on field measurements in the Damodar Valley coalfields of eastern India, suitable adsorption capacity has been noted in various coal blocks at the depth interval of 200$600 \mathrm{~m}$ (Singh and Hajra, 2018). Thus, we suggest updating the resource base that could be treated as storage sites based on the inventory data.

Reframing the criteria around storage depths will also lead to meaningful changes and improve industrial outlook for CBM production. Existing CBM production in India has been prominent in the coalfields of Raniganj, Jharia and East Bokaro. These coalfields have extensive deposits of coking coal (>13 Gt), which were not considered in prior studies. $\mathrm{CO}_{2}$ injection has a greater business opportunity when introduced later in the CBM well lifetime. If $\mathrm{CO}_{2}$ injection begins at year 15-20 since the inception of the well, it can improve productivity and lead to recovery of otherwise unrecoverable methane. As such, CBM production in these coalfields started in the early 2010s. The most recent biennial update report of the Indian Government to the United Nations Framework Convention of Climate Change (UNFCCC) indicates that CBM is being deployed as a clean coal technology within the government's decarbonization efforts. They indicate that fugitive methane emissions from coal mining and post-mining activities amounted to $17 \mathrm{Mt}$ $\mathrm{CO}_{2} \mathrm{e}$ (MOEFCC, 2021). As significant pre-mining drainage and deployment of CBM in virgin basins occur, it may also lead to a co-benefit of reduced fugitive emissions (Singh and Colosi, 2019). This means that significant ECBM opportunities might arise in this region around 2025-2030. Effective government policy-making and revised storage potential estimates based on our recommendations would, therefore, lead to heightened interest in the CBM fields in the region encouraging earlier CCS adoption.

\section{STORAGE POTENTIAL CONSIDERATIONS}

Shale gas production and utilization have dramatically transformed the North American and global natural gas landscape. Shale formations and their associated hydrocarbons have been found to be internationally abundant based on US EIA studies, although extraction largely depends on availability of massive fracturing equipment. Lately, work has also emerged looking at the viability of $\mathrm{CO}_{2}$ injection in such formations which could utilize their vast potential pore space. For instance, analyses in the mid-western US have shown considerable economic viability with this pathway, which results in $6-10 \%$ cost savings as compared to storage in saline aquifers (Bielicki et al., 2018). Similarly, life-cycle analyses have shown that gross injection of 1 ton of $\mathrm{CO}_{2}$ results in net sequestration of 0.96 ton of $\mathrm{CO}_{2}$ (Middleton et al., 2014; Menefee and Ellis, 2020), which reflects high viability with respect to the net-zero target. The life-cycle emissions here pertain to the upstream energy requirements in construction of the pipeline and storage infrastructure, as well as leakage involved.

There have been no nationwide or basinwide estimates of $\mathrm{CO}_{2}$ sequestration potential in India's shale reservoirs. But studies based in the United States showed a maximum theoretical storage capacity of $1.12 \mathrm{Mt}-\mathrm{CO}_{2}$ per square kilometer of area (Godec et al., 2013). The overall area of Indian shale basins is close to $1,00,000 \mathrm{~km}^{2}$ (Sain et al., 2014), which could result in comparable storage capacity as saline aquifers. However, estimating this is more difficult than that in coal seams because there is no commercial extraction of shale gas or oil in India. Moreover, the last of the prior sequestration potential estimates was carried out in 2008 and lab/field scale exploration of Indian shale basins began after that. That said, first-order potential estimates show 96-584 TCF of commercially-recoverable shale gas, as compared to only 92 TCF of CBM. Thus, we use the total organic carbon (TOC) of the shale formation as a proofof-concept for the possibility of $\mathrm{CO}_{2}$ sequestration in Indian shale formations. Tao and Clarens (2013) have shown the $\mathrm{CO}_{2}$ adsorption capacity is linearly related to TOC and accordingly could be treated as a proxy for understanding CCS viability. Figure 1A shows that the TOC for India's Damodar and Cambay basins is comparable or higher than the Eagle Ford basin where geologic injection has been deemed viable (Psarras et al., 2017). Damodar Valley shales exhibit an average TOC content of $8 \%$ by weight, with several outlier samples showing much higher values. The pore volumes of these shales have been found to be large and the adsorption ratio $\left(\mathrm{CO}_{2}-\mathrm{CH}_{4}\right)$ is also substantial at 2.6-6:1 (Bakshi et al., 2020). As we discuss in "Moving beyond theoretical potential," these factors are further complemented by geographical circumstances making the Damodar Valley an excellent candidate for localized storage. On the flip side, the area of this basin is limited $\left(3,600 \mathrm{~km}^{2}\right)$.

The methodology illustrated in Figure 1B should also be followed for other basins with lower geological and engineering feasibility for obtaining a technical estimate of the storage potential. The Krishna-Godaveri basin has the largest prospective volume $\left(\sim 1,460 \mathrm{~km}^{3}\right)$ of shale spread across depths of 4,000$16,400 \mathrm{~m}$, however, its lower TOC content limits the $\mathrm{CO}_{2}$ storage capacity. Similar is the case for Cauvery basin. The relatively lower TOC content in these basins is due to the presence of silt from nearby Krishna-Godaveri river deltas and relatively high sea-levels in case of Cauvery basin (Nagendra et al., 2014; Mani et al., 2016). Though the adsorption capacity per unit volume of shales is lower for Krishna-Godaveri and Cauveri basins, the larger area may mean cumulatively significant pore volume for $\mathrm{CO}_{2}$ storage.

While storage in shale formations is being considered as an alternative, there are two major inhibiting considerations. First, shale has been traditionally considered as the caprock for $\mathrm{CO}_{2}$ that may be stored in saline aquifers in the future (Song and Zhang, 2013). If the shale formation is itself considered a sink, it may affect the integrity of $\mathrm{CO}_{2}$ storage in underlying aquifers. Moreover, the geographic placement of $\mathrm{CO}_{2}$ injection wells may influence prospective gas production wells, which may affect overall economic prospects of the natural gas industry (Tao and Clarens, 2013). 
A

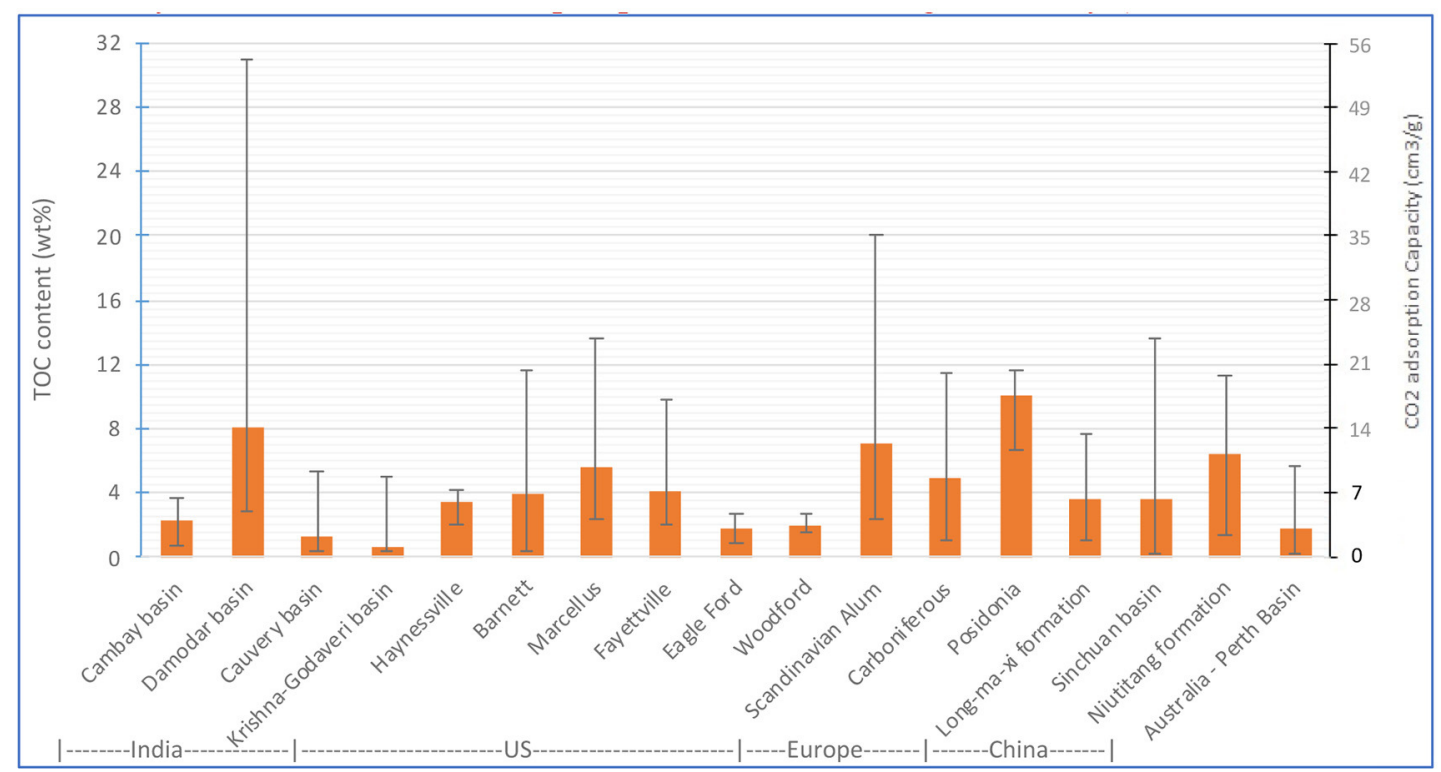

B

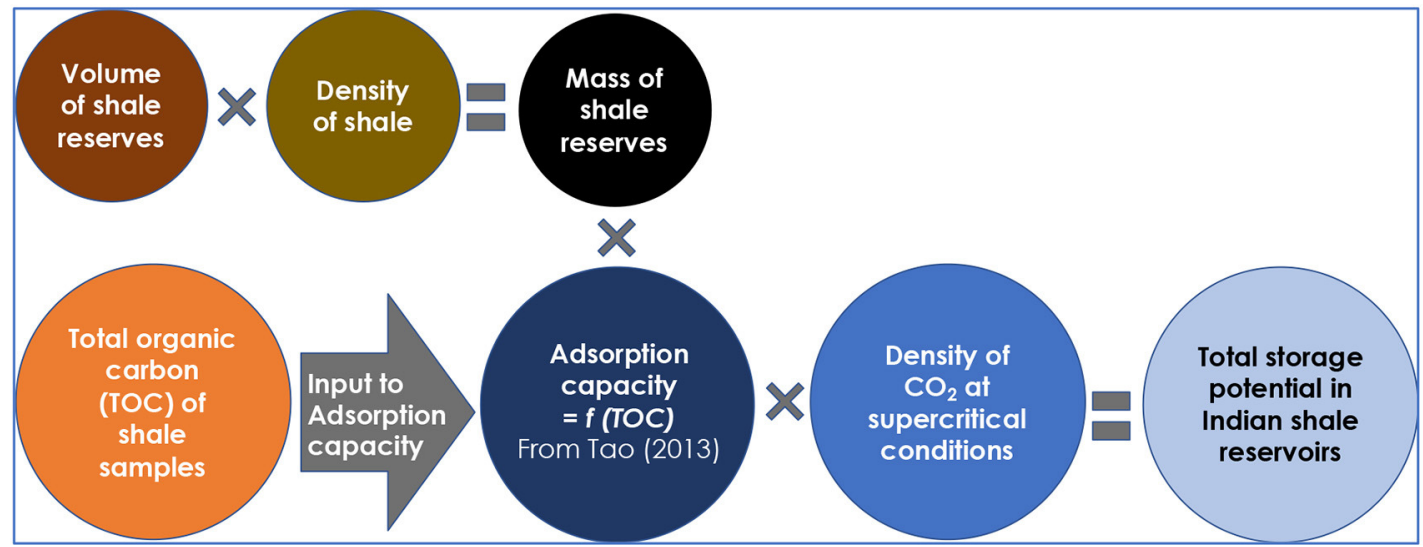

FIGURE 1 | (A) Total Organic Carbon (TOC) comparison of different shales explored worldwide. Data sources can be found in Supplementary Table 2 of the SI. Samples were collected at different depths for each of the basins and the TOC correspond to individual depths. The heights of the orange bars represent the medians of the values from the literature (Supplementary Table 2) and the ranges illustrate the variability of the TOC. (B) Suggested methodology to utilize TOC and existing volumetric data to estimate storage potential.

Figure $1 \mathrm{~A}$ also shows that the variation in TOC is very high depending on the depth. Similar heterogeneity may be seen in other parameters as well. As such, the uncertainty in estimation of storage potential may be very high and range in several orders of magnitude. Thus, the storage potential in the Marcellus basin as calculated by Tao and Clarens (2013) is $10-18$ Gt- $\mathrm{CO}_{2}$ while Edwards et al. (2015) estimate it at $<10 \mathrm{Gt}-\mathrm{CO}_{2}$. It should also be noted that the methodology provided in Tao and Clarens (2013) is identified as a screening mechanism at a national/regional scale estimation. In basins with greater detail of exploration, these have been further resolved using reservoir simulation to understand localized conditions. Notably, adsorption isotherm data can be utilized to understand the relative adsorption of methane and $\mathrm{CO}_{2}$ on shale structure. Gamma-ray and density log "cut off" are also used to understand pay zones where $\mathrm{CO}_{2}$ injection and gas recovery may be carried out economically. This, however, is subject to large uncertainty due to: limited isotherm data, lack of sustained production data, as well as representation of fractures in the simulations (Godec et al., 2013). It is also noteworthy that pilot-scale trials have not been carried out for $\mathrm{CO}_{2}$ injection in shales as opposed to coal seams. However, based on laboratory studies, some potential constraints in caprock seal efficiency, porosity reduction and reduced tensile strength have been noted (Fatah et al., 2020).

\section{MOVING BEYOND THEORETICAL POTENTIAL}

While we provide recommendations for revisiting the theoretical potential in unconventional formations, CCS best practices 


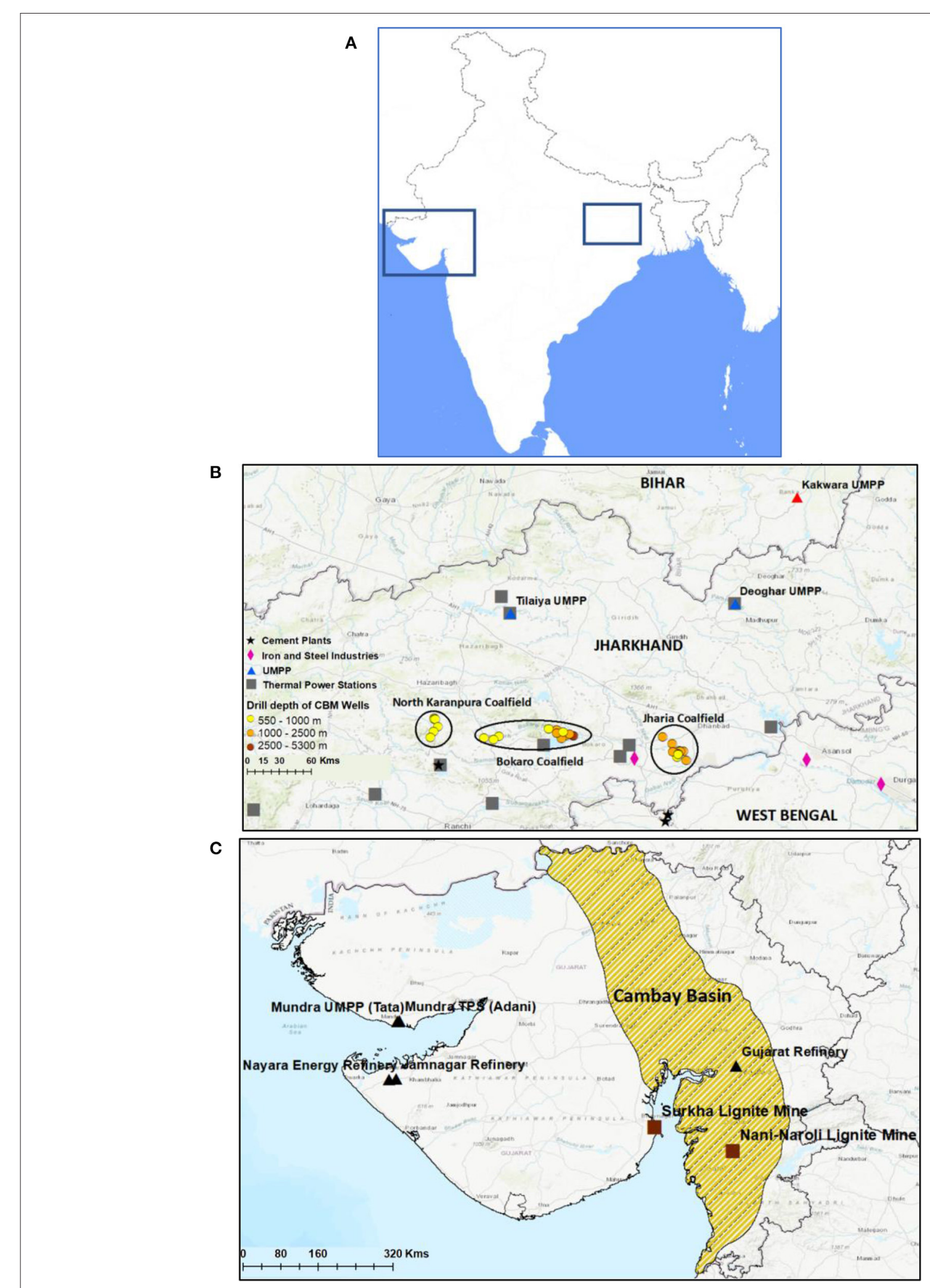

FIGURE 2 | Prospective CCS hubs could be centered around unconventional formations on the map of India (A) with insets showing eastern (B) and western India (C). UMPP: Ultra-mega power plant. 
(Supplementary Figure 1 of the SI) require its constraining with engineering, economic and source-sink mapping factors. It is important to understand the information that can be gathered using the studies already carried out and how it is distinct from proprietary industrial surveys. For instance, the primary issue with coal seam storage is induced swelling with $\mathrm{CO}_{2}$ injection i.e., reduction of permeability. A number of lab scale studies have been carried out to gauge these impacts. These studies reveal that while an initial exponential loss in permeability is seen due to $\mathrm{CO}_{2}$ injection, this could be managed by co-injection of nitrogen as well (Vishal, 2017a). Similarly, sorption time has been calculated for both shale and coal samples, which could provide an indication of the injectivity associated with these formations (Vishal, 2017b; Chandra et al., 2020). We suggest that initial studies could look at theoretical potential based on the recommendations presented in section Storage potential considerations in coal seams and then narrow it using factors such as swelling data, as these are publicly available.

Another area where academic research could focus on is the implications of source-sink mapping on storage potential. In the US, it has been pointed out that there are so-called " $\mathrm{CO}_{2}$ deserts," regions where sequestration sites are abundant but they are present far from the sources of $\mathrm{CO}_{2}$ (Middleton et al., 2014). This is not commonly seen in India due to high infrastructure density in selected industrial hubs. The two most prominent regions for $\mathrm{CO}_{2}$ storage in eastern and western India are seen in Figure 2. Eastern India has two upcoming ultramega power plants (power plants of $4 \mathrm{GW}$ each) which are anticipated to emit $\sim 25 \mathrm{Mt}-\mathrm{CO}_{2}$ every year. This is in addition to several existing steel plants and smaller power plants. The proximity of these large point sources is useful since around $10 \%$ of India's large-point sources' $\mathrm{CO}_{2}$ emissions are found in this region (Figure 2B). However, the only prominent sourcesink study carried out for this region did not assume storage in the coal or the shale formations of the Damodar Valley owing to insufficient storage pointed out by prior studies (Garg et al., 2017). The two major regional hubs shown in Figure 2 (Damodar and Cambay basins) along with two additional shale basins (Cauvery and Krishna-Godaveri) are in close proximity to point-sources with annual $\mathrm{CO}_{2}$ emissions of $328 \mathrm{Mt}-\mathrm{CO}_{2}$ as detailed in Supplementary Table 3 of the SI. Thus, for these basins to be considered as long-term sinks over a period of 30 years, their viable storage potential should be of the order of $10 \mathrm{Gt}-\mathrm{CO}_{2}$. If the viable potential is an order of magnitude less than the theoretical potential, the theoretical potential required in these basins is $100 \mathrm{Gt}-\mathrm{CO}_{2}$. Note that the point-sources are based on coal combustion and processing. In the future, if coal consumption declines, there may be some leeway in the required theoretical storage potential.

As pointed out in this paper, once the assumptions are reframed (section Storage potential considerations in coal seams) and shale basins are considered (section Storage potential considerations in shale formations), the storage in unconventional formations could increase by an order of magnitude. Similar fortuitous geographical conditions are present in the western part of the country in the Cambay
Basin (Figure 2C). This region has two large power plants with emissions higher than $25 \mathrm{Mt}-\mathrm{CO}_{2} /$ year each. The Jamnagar refinery in this region is the largest operating refinery in the world, which could provide low-cost $\mathrm{CO}_{2}$ capture opportunities. This refinery is already poised to received net-zero oil from the Permian Basin in the US (produced by coupling direct air capture with EOR) (Gupte and VanLaningham, 2021) and the downstream emissions could further be reduced by sequestration in Cambay basin shales. The lignite blocks in this region are also very suitable for underground coal gasification, which could again be a source of high-purity $\mathrm{CO}_{2}$. The government decarbonization efforts focus on coal gasification and creation of a methanol economy. As such, there is a targeted investment of $\$ 53$ billion for gasifying 100 Mt-coal by 2030 (MOEFCC, 2021). Global focus is increasingly shifting toward conceiving $\mathrm{CO}_{2}$ storage hubs or clusters which are areas with abundant sequestration potential and large concentration of large point sources (Global CCS Institute, 2020). The proof-of-concept maps here (Figure 2) show that these two regions could become hubs if the lucrative storage opportunities in unconventional formations are considered.

Other geologic factors are very dependent on the local injection conditions. For instance, caprock availability above the injection site is necessary to avoid $\mathrm{CO}_{2}$ migration and its interfering with groundwater. Moreover, when injection planning is done, it is desirable that the direction of the drilling is perpendicular to the natural fractures for reliable retention. While the stratigraphic data may not be publicly available, these are present as part of the investigation carried out by coal and oil companies. For instance, Coal India and ONGC have carried out detailed regional exploration of coalbed methane at the Jharia coalfield. Therefore, collaborations between the industry and academia could open up pathways to more detailed storage potential.

It may be also noted that this study aims at providing a systems level perspective for the $\mathrm{CO}_{2}$ storage potential in India. As such, it does not consider some of the field-level geologic parameters that affect overall geologic potential. When we refer to global studies such as Yu et al. (2019), it is noted that the actual storage potential may be an order of magnitude less than the theoretical storage potential. Our perspective does not delve into the engineering conditions that limit the storage potential because of the lack of large-scale $\mathrm{CO}_{2}$ injection field trials (Pashin et al., 2015). As and when the data from such trials become available, they may be combined with the primary data presented in this paper to arrive at a more refined storage potential. Further, in context of the proof-of-concept maps presented in Figure 2, we do not present a one-to-one correspondence between sources and sinks as studies in some other countries have attempted (Middleton et al., 2020). This is due to limited information in the Indian context about the prospective pipeline lengths. It would, therefore, be prudent for future studies to analyze the realistic costs of pipeline construction and operation to propose CCS clusters or hubs. 


\section{DATA AVAILABILITY STATEMENT}

The original contributions presented in the study are included in the article/Supplementary Material, further inquiries can be directed to the corresponding author.

\section{AUTHOR CONTRIBUTIONS}

US and JD contributed to framing of this paper. US and NS designed the figures. US wrote the first draft of the manuscript. NS and JD revised the draft. All authors

\section{REFERENCES}

ARI (1998). Enhanced Coal Bed Methane Recovery with $\mathrm{CO}_{2}$ Sequestration. International Energy Agency GHG RandD Programme. Available online at: https://www.adv-res.com/Coal-Seq_Consortium/ECBM_Sequestration_ Knowledge_Base/IEA\%20Reports\%20and\%20Presentations/Ph3_03\%20CO2 \%20ECBM\%20report.pdf

Bakshi, T., Vishal, V., Prusty, B. K., and Pathak, K. (2020). Carbon dioxide and methane sorption characteristics of Damodar Valley and Upper Assam shale, India. Energy Clim. Change 1:100002. doi: 10.1016/j.egycc.2020.100002

Benson, S., Cook, P., Anderson, J., Bachu, S., Nimir, H. B., Basu, B., et al. (2005). Underground Geologic Storage. IPCC Special Report on Carbon dioxide Capture and Storage. Cambridge: Cambridge University Press.

Bielicki, J. M., Langenfeld, J. K., Tao, Z., Middleton, R. S., Menefee, A. H., and Clarens, A. F. (2018). The geospatial and economic viability of $\mathrm{CO}_{2}$ storage in hydrocarbon depleted fractured shale formations. Int. J. Greenhouse Gas Control 75, 8-23. doi: 10.1016/j.ijggc.2018.05.015

Blondes, M. S., Gans, K. D., Rowan, E. L., Thordsen, J. J., Reidy, M. E., Engle, M. A., et al. (2016). US Geological Survey National Produced Waters Geochemical Database v2. 2 Documentation. Reston, VA: USGS Energy Resources Program: Produced Waters, USGS.

Chandra, D., Vishal, V., Debbarma, A., Banerjee, S., Pradhan, S. P., and Mishra, M. K. (2020). Role of composition and depth on pore attributes of barakar formation gas shales of ib valley, India, using a combination of low-pressure sorption and image analysis. Energy Fuels 34, 8085-8098. doi: 10.1021/acs.energyfuels.0c00746

Chaudhary, A., Rathi, A., and Singh, R. K. (2021). India Considers 2050 Net-Zero Target, a Decade Before China. Bloomberg Green. Available online at: https:// www.bloomberg.com/news/articles/2021-03-17/india-considers-net-zerogoal-around-2050-a-decade-before-china (accessed May 11, 2021).

Das, S., and Dutta, P. (2017). Preliminary understanding of $\mathrm{CO}_{2}$ sequestration and enhanced methane recovery in Raniganj coalfield of India by reservoir simulation. Energy Procedia 114, 4643-4657. doi: 10.1016/j.egypro.2017.03.1267

del Real, P. G., and Vishal, V. (2016). "Mineral carbonation in ultramafic and basaltic rocks," in Geologic Carbon Sequestration (Cham: Springer), 213-229. doi: 10.1007/978-3-319-27019-7_11

DOE (2015). Carbon Utilization and Storage Atlas-Fourth Edition (Atlas V), US Department of Energy. Available online at: https://www.netl.doe.gov/coal/ carbon-storage/strategic-program-support/natcarb-atlas (accessed March 21, 2021).

Dooley, J. J., Kim, S. H., Edmonds, J. A., Friedman, S. J., and Wise, M. A. (2005). "A first-order global geological $\mathrm{CO}_{2}$-storage potential supply curve and its application in a global integrated assessment model," in Greenhouse Gas Control Technologies (New York, NY: Oxford), 7.

Edwards, R. W., Celia, M. A., Bandilla, K. W., Doster, F., and Kanno, C. M. (2015). A model to estimate carbon dioxide injectivity and storage capacity for geological sequestration in shale gas wells. Environ. Sci. Technol. 49, 9222-9229. doi: 10.1021/acs.est.5b01982 contributed to manuscript revision, read, and approved the submitted version.

\section{ACKNOWLEDGMENTS}

The authors thanks the Northwestern Open Access Fund for covering the article processing charges.

\section{SUPPLEMENTARY MATERIAL}

The Supplementary Material for this article can be found online at: https://www.frontiersin.org/articles/10.3389/fclim. 2021.708320/full\#supplementary-material

Fatah, A., Bennour, Z., Ben Mahmud, H., Gholami, R., and Hossain, M. (2020) A review on the influence of $\mathrm{CO}_{2}$ /shale interaction on shale properties: implications of CCS in shales. Energies 13:3200. doi: 10.3390/en13123200

Garg, A. (2021). How India can achieve its net-zero emissions goal. The Economic Times. Available online at: https://economictimes.indiatimes.com/ industry/renewables/view-how-india-can-achieve-its-net-zero-emissionsgoal/articleshow/81901910.cms?from=mdr (accessed May 11, 2021).

Garg, A., Shukla, P. R., Parihar, S., Singh, U., and Kankal, B. (2017). Costeffective architecture of carbon capture and storage (CCS) grid in India. Int. J. Greenhouse Gas Control 66, 129-146. doi: 10.1016/j.ijggc.2017.09.012

Global CCS Institute (2020). Global Status of CCS-2020. Available online at: https://www.globalccsinstitute.com/resources/global-status-report/ (accessed March 18, 2021).

Godec, M., Koperna, G., Petrusak, R., and Oudinot, A. (2013). Potential for enhanced gas recovery and $\mathrm{CO}_{2}$ storage in the Marcellus Shale in the Eastern United States. Int. J. Coal Geol. 118, 95-104. doi: 10.1016/j.coal.2013.05.007

Gupta, A., and Paul, A. (2019). Carbon capture and sequestration potential in India: a comprehensive review. Energy Procedia 160, 848-855. doi: 10.1016/j.egypro.2019.02.148

Gupte, E., and VanLaningham, P. (2021). US' Occidental Supplies First Cargo of 'Carbon-Neutral Crude' to India's Reliance. Available online at: https:// www.spglobal.com/platts/en/market-insights/latest-news/oil/012921-usoccidental-supplies-first-cargo-of-carbon-neutral-crude-to-indias-reliance (accessed May 11, 2021)

Hiremath, M., Viebahn, P., and Samadi, S. (2021). An integrated comparative assessment of coal-based carbon capture and storage (CCS) Vis-à-Vis renewable energies in India's low carbon electricity transition scenarios. Energies 14:262. doi: 10.3390/en14020262

Holloway, S., Garg, A., Kapshe, M., Deshpande, A., Pracha, A. S., Khan, S. R., et al. (2009). An assessment of the $\mathrm{CO}_{2}$ storage potential of the Indian subcontinent. Energy Procedia 1, 2607-2613. doi: 10.1016/j.egypro.2009.02.027

IEA CCC (2021). A Pathway to Reducing Emissions from Coal Power in India. London WC: IEA Clean Coal Center.

Mahanta, B., and Vishal, V. (2020). " $\mathrm{CO}_{2}$ sequestration and enhanced coalbed methane recovery: worldwide status and Indian scenario," in Applied Geology (New York, NY: Springer), 161-181.

Malik, A., Bertram, C., Despres, J., Emmerling, J., Fujimori, S., Garg, A., et al. (2020). Reducing stranded assets through early action in the Indian power sector. Environ. Res. Lett. 15:094091. doi: 10.1088/1748-9326/ab8033

Mani, D., Ratnam, B., Kalpana, M. S., Patil, D. J., and Dayal, A. M. (2016). Elemental and organic geochemistry of Gondwana sediments from the Krishna-Godavari Basin, India. Geochemistry 76, 117-131. doi: 10.1016/j.chemer.2016.01.002

Menefee, A. H., and Ellis, B. R. (2020). Regional-scale greenhouse gas utilization strategies for enhanced shale oil recovery and carbon management. Energy Fuels 34, 6136-6147. doi: 10.1021/acs.energyfuels.0c00562

Middleton, R. S., Clarens, A. F., Liu, X., Bielicki, J. M., and Levine, J. S. (2014) $\mathrm{CO}_{2}$ deserts: implications of existing $\mathrm{CO}_{2}$ supply limitations for carbon management. Environ. Sci. Tech. 48, 11713-11720. doi: 10.1021/es5022685 
Middleton, R. S., Yaw, S. P., Hoover, B. A., and Ellett, K. M. (2020). SimCCS: an open-source tool for optimizing $\mathrm{CO}_{2}$ capture, transport, and storage infrastructure. Environ. Modell. Softw. 124:104560. doi: 10.1016/j.envsoft.2019.104560

MOEFCC (2021). India: Third Biennial Update Report to the United Nations Framework Convention on Climate Change. Ministry of Environment, Forest and Climate Change, Government of India.

Nagendra, R., Sathiyamoorthy, P., Reddy, A. N., Gilbert, H., and Jaiprakash, B. C. (2014). Stratigraphic status, age, and paleobathymetry of the grey shale member, dalmiapuram formation, Cauvery Basin, India. Arabian J. Geosci. 7, 4133-4144. doi: 10.1007/s12517-013-1062-7

Parikh, J., and Parikh, K. (2021). "Weighing our net zero challenge: It's not just about energy," in India has to Assess Technological, Economic and Societal Transitions (New Delhi: The Times of India). Available online at: https:// timesofindia.indiatimes.com/blogs/toi-edit-page/weighing-our-net-zerochallenge-its-not-just-about-energy-india-has-to-assess-technologicaleconomic-and-societal-transitions/ (accessed May 11, 2021)

Pashin, J. C., Clark, P. E., McIntyre-Redden, M. R., Carroll, R. E., Esposito, R. A., Oudinot, A. Y., et al. (2015). SECARB $\mathrm{CO}_{2}$ injection test in mature coalbed methane reservoirs of the Black Warrior Basin, Blue Creek Field, Alabama. Int. J. Coal Geol. 144, 71-87. doi: 10.1016/j.coal.2015.04.003

Psarras, P., Holmes, R., Vishal, V., and Wilcox, J. (2017). Methane and $\mathrm{CO}_{2}$ adsorption capacities of kerogen in the Eagle Ford shale from molecular simulation. Acc. Chem. Res. 50, 1818-1828. doi: 10.1021/acs.accounts.7b00003

Sain, K., Rai, M., and Sen, M. K. (2014). A review on shale gas prospect in Indian sedimentary basins. J. Indian Geophys. Union 18, 183-194.

Selosse, S., and Ricci, O. (2017). Carbon capture and storage: Lessons from a storage potential and localization analysis. Appl. Energy 188, 32-44. doi: 10.1016/j.apenergy.2016.11.117

Shukla, P. R., Dhar, S., Pathak, M., Mahadevia, D., and Garg, A. (2015). Pathways to Deep Decarbonization in India, SDSN-IDDRI. Available online at: https://www. iddri.org/sites/default/files/import/publications/ddpp_2015synthetisreport. pdf (accessed February 8, 2021).

Singh, A.K., and Mohanty, D. (2015). " $\mathrm{CO}_{2}$ Sequestration potential of Indian coalfields," in Carbon Capture, Storage and, Utilization: A Possible Climate Change Solution for Energy Industry, eds M. Goel, M. Sudhakar, and R. V. Shahi, (New Delhi: TERI Press), 133-147.

Singh, A. K., and Hajra, P. N. (2018). Coalbed Methane in India: Opportunities, Issues and Challenges for Recovery and Utilization. New York, NY: Springer.

Singh, A. K., and Kumar, J. (2016). Fugitive methane emissions from Indian coal mining and handling activities: estimates, mitigation and opportunities for its utilization to generate clean energy. Energy Procedia 90, 336-348.

Singh, U., and Colosi, L. M. (2019). Water-energy sustainability synergies and health benefits as means to motivate potable reuse of coalbed methaneproduced waters. Ambio 48, 752-768. doi: 10.1007/s13280-018-1098-8

Singh, U., Rao, A. B., and Chandel, M. K. (2017). Economic implications of $\mathrm{CO}_{2}$ capture from the existing as well as proposed coal-fired power plants in India under various policy scenarios. Energy Procedia 114, 7638-7650. doi: 10.1016/j.egypro.2017.03.1896
Singh, A. K., Mendhe, V. A., and Garg, A. (2006). " $\mathrm{CO}_{2}$ sequestration potential of geological formations of India," in Proceedings of the 8th International Conference on Greenhouse Gas Technologies (Oxford: Elsevier Science).

Song, J., and Zhang, D. (2013). Comprehensive review of caprock-sealing mechanisms for geologic carbon sequestration. Environ. Sci. Tech. 47, 9-22. doi: 10.1021/es301610p

Spencer, T., Colombier, M., Sartor, O., Garg, A., Tiwari, V., Burton, J., et al. (2018). The $1.5 \mathrm{C}$ target and coal sector transition: at the limits of societal feasibility. Climate Policy 18, 335-351. doi: 10.1080/14693062.2017. 1386540

Tao, Z., and Clarens, A. (2013). Estimating the carbon sequestration capacity of shale formations using methane production rates. Environ. Sci. Tech. 47, 11318-11325. doi: 10.1021/es401221j

Vishal, V. (2017a). In-situ disposal of $\mathrm{CO}_{2}$ : liquid and supercritical $\mathrm{CO}_{2}$ permeability in coal at multiple down-hole stress conditions. J. $\mathrm{CO}_{2}$ Util. 17, 235-242. doi: 10.1016/j.jcou.2016.12.011

Vishal, V. (2017b). Saturation time dependency of liquid and supercritical $\mathrm{CO}_{2}$ permeability of bituminous coals: implications for carbon storage. Fuel 192, 201-207. doi: 10.1016/j.fuel.2016.12.017

Vishwanathan, S. S., and Garg, A. (2020). Energy system transformation to meet NDC, $2^{\circ} \mathrm{C}$, and well below $2^{\circ} \mathrm{C}$ targets for India. Clim. Change 162, 1877-1891. doi: 10.1007/s10584-019-02616-1

Wuppertal (2012). CCS global: Prospects of Carbon Capture and Storage Technologies (CCS) in Emerging Economies, Final Report to the German Federal Ministry for the Environment, Nature Conservation and Nuclear Safety (BMU). Available online at: https://wupperinst.org/en/p/wi/p/s/pd/208 (accessed February 8, 2021).

Yadav, D., Chandel, M. K., and Kumar, P. (2016). Suitability of $\mathrm{CO}_{2}$ capture technologies for carbon capture and storage in India. Greenhouse Gases 6, 519-530. doi: 10.1002/ghg.1579

Yu, S., Horing, J., Liu, Q., Dahowski, R., Davidson, C., Edmonds, J., et al. (2019). CCUS in China's mitigation strategy: insights from integrated assessment modeling. Int. J. Greenhouse Gas Control 84, 204-218. doi: 10.1016/j.ijggc.2019.03.004

Zhou, F., Hou, W., Allinson, G., Wu, J., Wang, J., and Cinar, Y. (2013). A feasibility study of ECBM recovery and $\mathrm{CO}_{2}$ storage for a producing $\mathrm{CBM}$ field in Southeast Qinshui Basin, China. Int. J. Greenhouse Gas Control 19, 26-40. doi: 10.1016/j.ijggc.2013.08.011

Conflict of Interest: The authors declare that the research was conducted in the absence of any commercial or financial relationships that could be construed as a potential conflict of interest.

Copyright (c) 2021 Singh, Sharma and Dunn. This is an open-access article distributed under the terms of the Creative Commons Attribution License (CC BY). The use, distribution or reproduction in other forums is permitted, provided the original author(s) and the copyright owner(s) are credited and that the original publication in this journal is cited, in accordance with accepted academic practice. No use, distribution or reproduction is permitted which does not comply with these terms. 